\title{
Is a Salinity Monitoring Network "Worth Its Salt"?
}

Saltwater intrusion threatens the water supplies of many coastal communities. Management of these water supplies requires well-designed and properly maintained and operated salinity monitoring networks. Long-standing deficiencies identified in a salinity monitoring network in southwest Florida during a 2013 study (Prinos, 2013) help to illustrate the types of problems that can occur in aging and poorly maintained networks. This cooperative U.S. Geological Survey (USGS) and South Florida Water Management District (SFWMD) study also describes improvements that can be implemented to overcome these deficiencies.

\section{Introduction}

Saltwater intrusion of primary water-use aquifers in southwest Florida resulted from installation of drainage canals, leakage through poorly cased wells, and withdrawals from water-supply wells. Saltwater intruded through various pathways (fig. 1) to create the current distribution of saltwater in southwest Florida's aquifers. Saltwater intrusion led to abandonment of the City of Naples first well field in 1945, and to the replacement of its second well field in 1954. Samples from groundwater monitoring wells indicate that saltwater intrusion continues; however, existing deficiencies lead to uncertainty in the extent and distribution of saltwater within the aquifer.

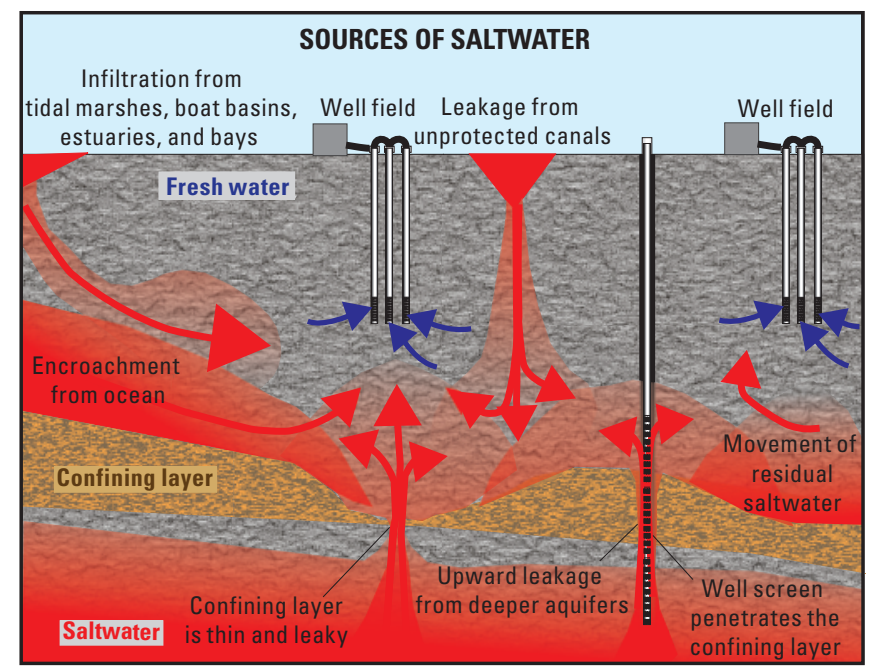

Figure 1. The saltwater that intruded the aquifers of southwest Florida emanates from multiple sources. Figure modified from Prinos (2013).

The majority of salinity monitoring in southwest Florida is conducted to fulfill water-use permit requirements. This monitoring is managed by the SFWMD. Monitoring includes data from 519 wells in the water table and lower Tamiami aquifers near the following well fields: the City of Naples Coastal Ridge, Bonita Springs, Collier County Public Water Supply Golden Gate, Golden Gate Water Treatment, and the City of Naples East Golden Gate (fig. 2).

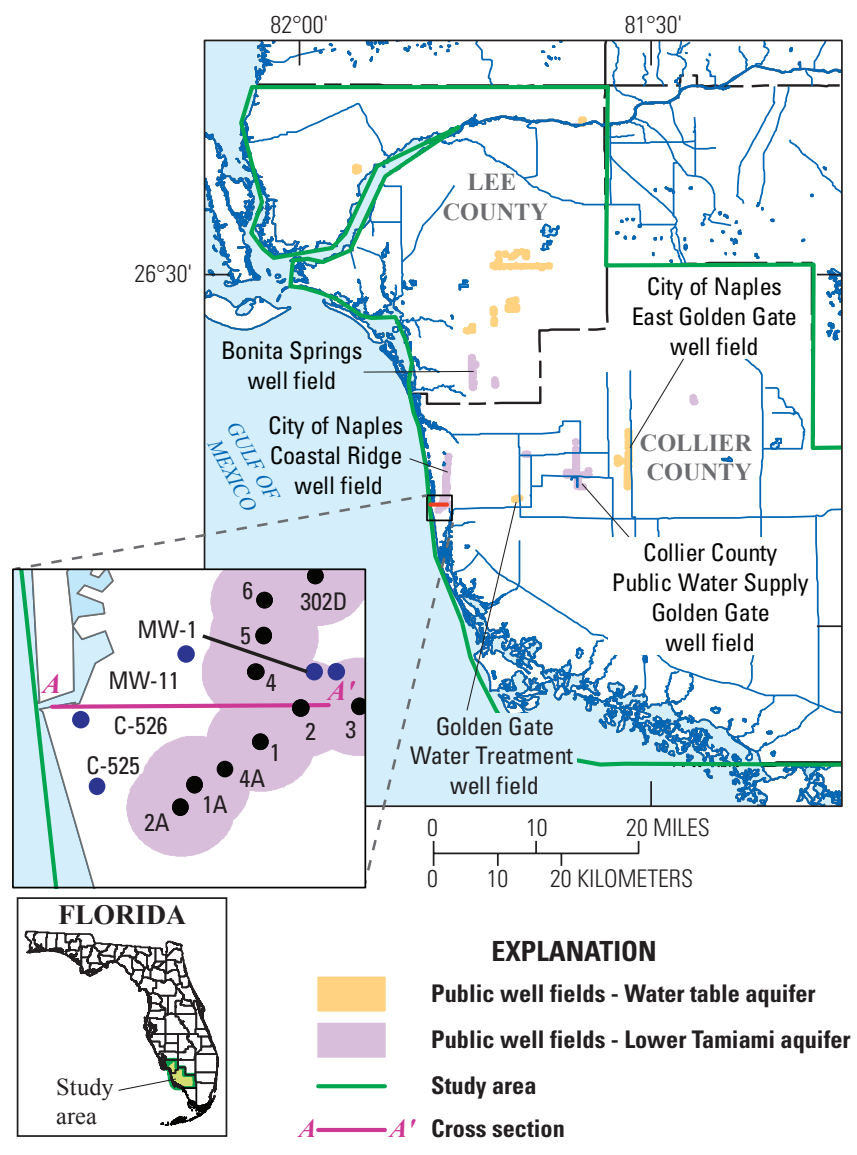

Figure 2. Study area, public well fields, and cross sections.

\section{Deficiencies}

Prinos (2013) identified deficiencies in this monitoring, including the following:

- The existing network does not provide sufficient information to differentiate between the multiple sources of saltwater intrusion or to map the distribution of saltwater in the aquifer.

- Many of the existing monitoring wells do not fully penetrate the aquifers of interest (fig. 3). It is uncertain, therefore, whether saltwater occurs below these wells.

- Monitoring is densely clustered around well fields, but sparse near the saltwater front. This distribution of monitoring may detect saltwater near the well fields but may not provide sufficient warning.

- Some damaged or destroyed wells have not been repaired or replaced.

- Many wells used for salinity monitoring have open intervals longer than $20 \mathrm{ft}$, and can yield samples that are not representative of maximum salinity in the aquifer. 
- Some of the sampling protocols being used do not consider the greater density of saltwater relative to freshwater. These protocols can result in saltwater samples that have been diluted with freshwater.

- Some wells are open to multiple aquifers.

An example of these deficiencies is depicted in figure 3. A recent map of saltwater intrusion indicated that the $250 \mathrm{mg} / \mathrm{L}$ isochlor was inland of this well field, yet previous studies had indicated freshwater beneath this well field (Prinos, 2013). If saltwater exists below the well field, it can potentially upcone and contaminate it. For this reason, it is crucial to have wells that monitor the full thickness of the aquifer. Many of the same deficiencies described by Prinos (2013) were described by Klein (1980), and by Burns and Shih (1984).

\section{Improvements}

Deficiencies in the existing network can be addressed through the installation of new polyvinyl chloride-cased, multidepth, short-screened (5-ft) monitoring wells (fig. 4) that are designed to sample water from the base of the aquifer, near the leading edge of the saltwater front. These wells could be designed for electromagnetic induction logging, which can detect changes in resistivity caused by saltwater intrusion throughout the full thickness of the aquifer. Geochemical analysis of samples can differentiate between sources of saltwater. Sampling protocols can be improved by considering water density. Surface or airborne geophysical examinations aid in mapping this front. Network operation, management, and quality assurance can be improved.

By avoiding the deficiencies and implementing the improvements described for the salinity monitoring network in southwest Florida, coastal communities can ensure that the data needed to evaluate saltwater intrusion is reliable. They can evaluate whether their own salinity networks are worth their salt.

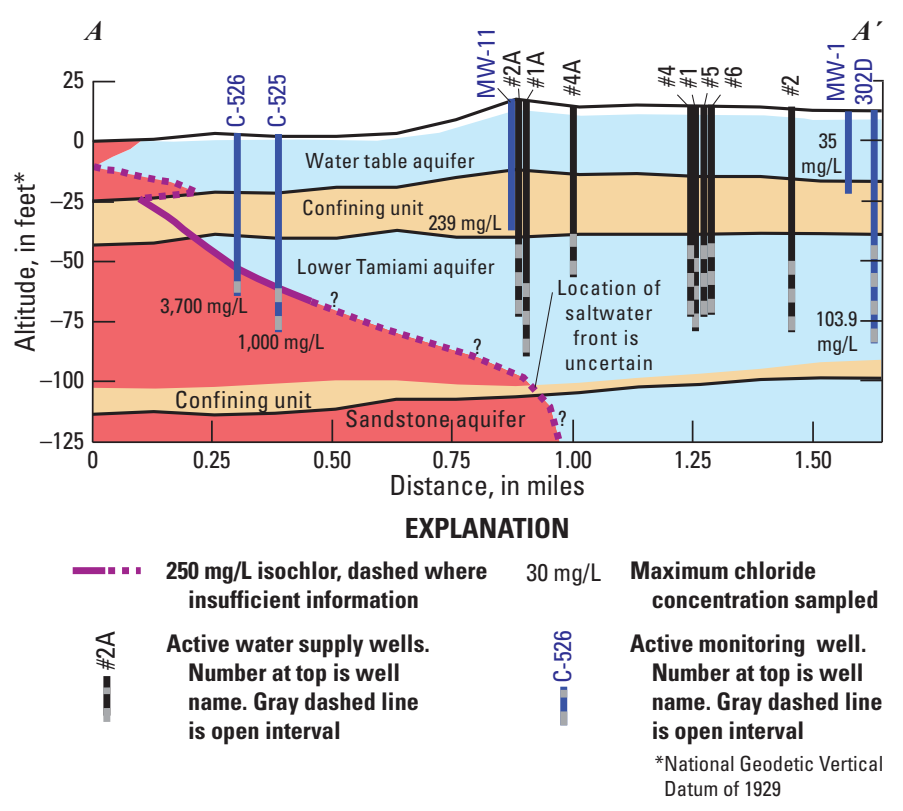

Figure 3. Section through southern part of the City of Naples Coastal Ridge well field. Location of section is shown in figure 2. Figure modified from Prinos (2013).

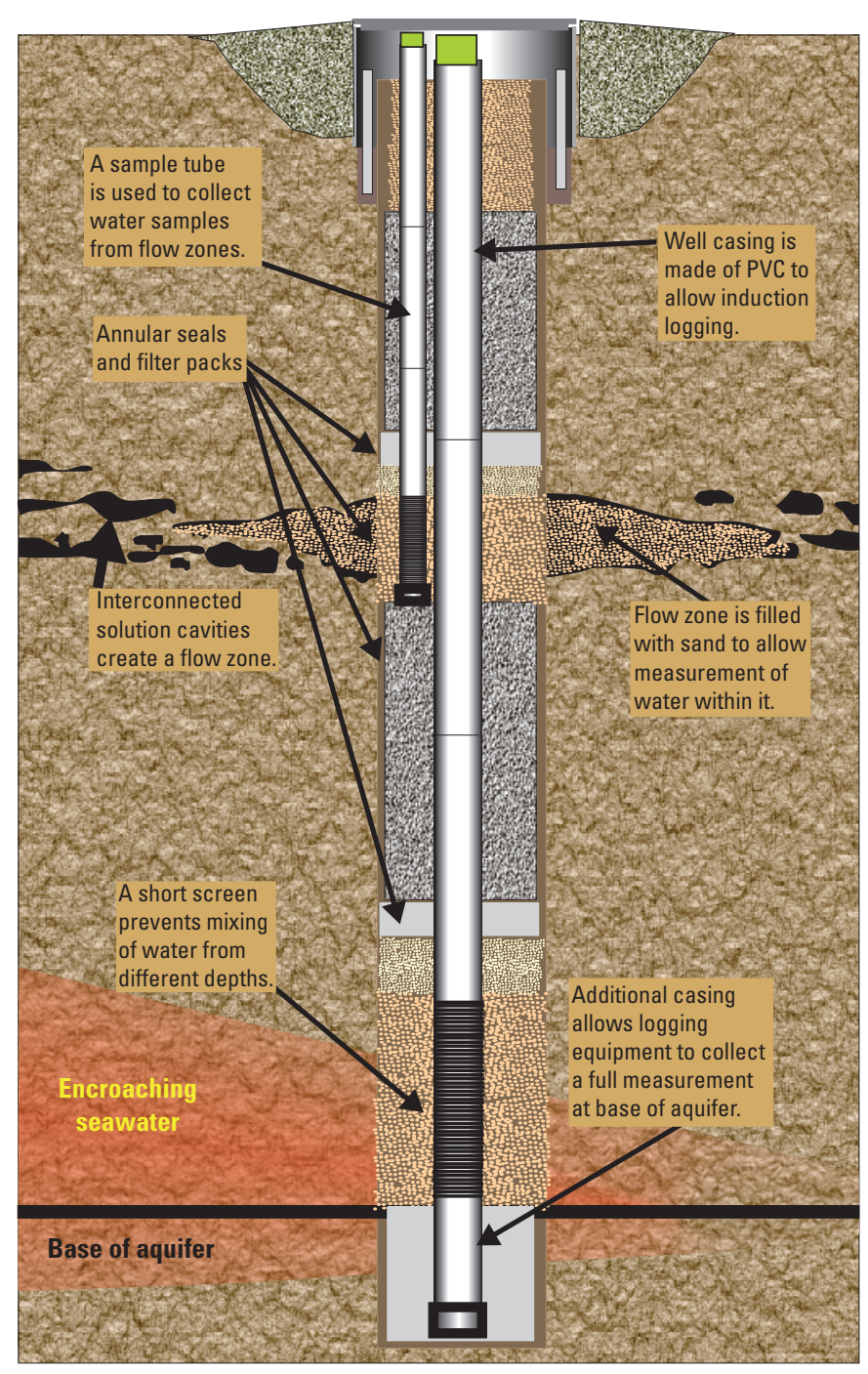

Figure 4. Schematic of a well designed for electromagnetic induction logging; well casing is made of polyvinyl chloride (PVC).

\section{References Cited}

Burns, W.S., and Shih, George, 1984, Preliminary evaluation of the groundwater monitoring network in Collier County, Florida: Big Cypress Basin Board of the South Florida Water Management District, DRE 181, 46 p., 2 apps.

Klein, Howard, 1980, Water-resources investigations, Collier County, Florida: U.S. Geological Survey Open-File Report 80-1270, 29 p.

Prinos, S.T., 2013, Saltwater intrusion in the surficial aquifer system of the Big Cypress Basin, southwest Florida, and a proposed plan for improved salinity monitoring:

U.S. Geological Survey Open-File Report 2013-1088, 58 p., http://pubs.usgs.gov/of/2013/1088/.

By Scott T. Prinos

stprinos@usgs.gov

\section{For more information, contact:}

Director, USGS Florida Water Science Center

4446 Pet Lane, Suite 108

Lutz, FL 33559

http://fl.water.usgs.gov 